\title{
South Africa's Inflation Persistence: a Quantile Regression Framework
}

\author{
Rangan Gupta $\quad$ Charl Jooste $\quad$ Omid Ranjbar
}

\begin{abstract}
We study inflation persistence in South Africa using a quantile regression approach. We control for structural breaks using a quantile structural break test on a long span of inflation data. Our study includes persistence estimates for headline and core inflation - thus controlling for possible biases emanating from extremely volatile periods. South Africa's inflation persistence is lowest during the inflation targeting period regardless of the inflation measure. Inflation persistence is also constant over all quantiles during the inflation targeting regime for core inflation. There is a difference between the estimates from headline and core - headline persistence increases in relation to higher quantiles. Thus energy and food price shocks might de-stabilise inflation altogether.
\end{abstract}

Keywords: Inflation persistence, quantile regression, structural breaks

JEL Codes: C21, E31

\footnotetext{
- Corresponding author. Department of Economics, University of Pretoria, Pretoria, 0002, South Africa. Email: rangan.gupta@up.ac.za.

^Department of Economics, University of Pretoria, Pretoria, 0002, South Africa. Email: Jooste.Charl@yahoo.co.za.

• Ministry of Industry, Mine and Trade, Tehran, Iran. Email: omid.ranjbar61@gmail.com.
} 


\section{Introduction}

The study of inflation persistence is popular in South Africa. It varies from identifying the unit root property of inflation in simple models to more complicated models in a multivariate, multistate setup. The parameter values of inflation persistence tell policy makers whether they are able to maintain price stability - the core mandate of the South African Reserve Bank (SARB). Targeting inflation would seem like a futile pursuit if inflation exhibits a unit root, despite a monetary authority trying its best to anchor inflation expectations and given sufficient time to so. Alas, if inflation is mean reverting, the monetary policy authority could maintain price stability. It is possible that inflation persistence differs at various levels of inflation. Knowing these ranges, levels or corridors will help monetary policy in setting rates when deviations from target occur and will warn them about the problems and difficulties of stabilising prices if it becomes explosive. This study attempts to fill an important gap in the South African literature. We estimate inflation persistence at various quantiles and over different inflation regimes. We argue that the distribution of inflation persistence is more important than merely knowing how persistent mean inflation is. Explosive paths for inflation across all quantiles would suggest that the SARB failed at stabilising prices and at anchoring inflation expectations. Conversely, low persistence estimates over the entire distribution would imply that even short run deviations from the target are temporary and strengthens the idea that the SARB has anchored expectations reasonably well.

This study also reinforces the results from previous studies - we show that inflation persistence has been lower since inflation targeting and contrast it against other policy regimes using data that encompasses a long history of inflation. The results also highlight the usefulness of mean inflation to study inflation persistence.

Sample periods and methodologies differentiate the large body of inflation persistence studies. Methodologies range from summing up the lagged coefficients of inflation (see Clark, 2006; Pivetta and Reis, 2007; Batini, 2002 and Levin and Piger, 2004), to mutlivariate settings (see Cogley and Sargent, 2002; Cogley and Sargent, 2006), to nonlinear specifications (see Amisano and Tristani, 2007). This study borrows a significant amount from Tillman and Wolters (2015). They study US inflation persistence over time using a quantile regressions, which differ from previous methodologies. This method allows them to study the persistence of inflation during different regimes and for different values of inflation - the conditional distribution. For the US, they show that there is evidence of structural breaks in inflation persistence in the 1950's and the 1980 's. Furthermore, inflation persistence has moderated and become similar across quantiles after the Volcker period. Inflation exhibits unit root behaviour before 1980, but since the end of the Volcker period the unit root is rejected at each quantile. They suggest that inflation can be decomposed into shocks emanating from monetary policy and inflation persistence shocks, where the latter is of particular interest. In using the methodology of Oka and Qu (2011) they are 
able to study the "synchronised" movements of inflation across all quantiles and whether the mean inflation is informative about the entire distribution of inflation.

Macroeconomic theory provides some explanations for persistent inflation. Lags of inflation in simple empirical models are often justified on the basis of how expectations are formed (mostly backward looking inflation) or serves as a proxy for price setting frictions (Fuhrer, 2011). Inflation rigidity is also often stated as a key determinant of inflation. The models by Calvo (1983) explicitly account price inertia in a model of contracts and the way firms reset prices. Other interesting work from the inflation literature touches on inflation asymmetry due to convexities in the Phillips curve - such as in Laxton et al. (1999). As an example shocks during recessions may be absorbed through employment, hence hardly having an impact on wages and inflation - and thus explaining why inflation is rigid downward and flexible and persistent upward. With menu costs downward price stickiness can be imposed endogenously. Large shocks move prices while small shocks have little effect. However, as shown by Caballero and Engle (1993) and Ball and Mankiw (1994) positive and negative shocks to inflation do not have the same size effects. Here firms that want to lower their relative price can do so by simply waiting for mean inflation. Firms will pay the menu costs to prevent a gap between their desired relative price and that of the falling relative price due to positive demand shocks (Tillman and Wolters, 2015).

The study by Tillman and Wolters (2015) is related to Tsong and Lee (2011) but innovates by assessing the time variation in persistence in different quantiles. Tsong and Lee (2011) study the asymmetry of inflation persistence for 12 OECD countries using the using the methodology developed by Koenker and Xiao (2004). Inflation is mean reverting, but the dynamic adjustments are asymmetric. Negative shocks are associated with quick mean reversion while inflation is persistent with large positive shocks.

Some weaknesses of quantile regression modelling have been put forth by Manzan and Zerom (2015). They argue that the AR quantile regression estimates for inflation persistence are biased when not controlling for inflation volatility. They test the out-of-sample forecast predictions of the quantile autoregression against an AR model accounting for volatility where the different quantiles of inflation enter the volatility equation. They show that the AR model outperforms the quantile regressions (QAR) and that the persistence parameter is quite high and compares favourably with Stock (2002) - accounting for volatility - thus when volatility is ignored the persistence parameter seems underestimated. The results are reversed when considering headline inflation only - persistence has decreased to very low levels in the mid 2000's. Given the differences in headline and core inflation, they attribute the asymmetric effects stemming from the QAR due to heteroskedasticity - thus a misspecified equation. We address this issue by using a measure of core inflation that removes excess volatility. Finally, they show that inflation is stationary over low quantiles but exhibits a unit root at high quantiles using the quantile unit root test of Koenker and Xiao (2004). 
There has been a surge of papers recently regarding estimates of core inflation and inflation persistence in South Africa. Rangasamy (2009) uses the well-known univariate autoregressive (AR) equation to obtain a measure of persistence in aggregate as well as disaggregated inflation. This method relies on estimating various AR terms where inflation is the dependent variable. The regression often includes a constant. The sum of the AR terms, $\rho=\sum_{i=1}^{n} \alpha_{i}$ where $\rho \in(0,1)$, determines the degree of persistence and $\alpha_{i}$ is the parameter on lagged inflation. If $\rho \geq 1$ then inflation contains a unit root and is explosive. If $\rho<1$ then inflation is mean reverting. $\mathrm{He}$ shows that there has been a decline in persistence since the adoption of inflation targeting in 2000 ( $\rho=0.98$ before inflation targeting and $\rho=0.83$ since inflation targeting). These estimates are still very persistent despite inflation reverting back to its mean. Interestingly he shows that disaggregated inflation indices are less persistent compared to the aggregate measure - thus hinting at an aggregation bias.

Balcilar et al. (2015) use a fractionally integrated model in a regime switching setup to study inflation persistence. The fractionally integrated model allows for inflation persistence to be very long (i.e. approaching a unit root). The Markov-switching setup derives persistence estimates for inflation in high inflation and low inflation states. They show that inflation persistence is much stronger in a high inflation environment compared to a low inflation environment - while controlling for volatile inflation states. Balcilar et al. (2015) come to a similar conclusion as Rangasamy (2009) - inflation persistence is much lower since inflation targeting (although the date for the low inflation state starts in 2003 - implying that it took a while to anchor inflation expectations). According to their model specification, South Africa has been in a low inflation state since 2003. The policy recommendations are clear - controlling inflation becomes very difficult once the SARB allows inflation to breach high levels and as a consequence will have to deal with high inflation for a long period. The half-life for inflation during a high inflation period is 70 months compared to 10 months in a low inflation state.

Using an approach that relies on micro foundations, Du Plessis and Burger (2013) estimate a New Keynesian Phillips curve that allows for firms to index current prices to past inflation and future inflation - a measure of persistence. The parameter on past inflation, however, has the opposite sign in some specifications. Only when two restrictions are imposed (one where the discount parameter equals unity and another where the forward and backward parameters sum to unity) do they obtain a positive value. It is definitely very interesting that the forward looking parameter has a larger weight in explaining current inflation than the backward indexation, meaning that the persistence on inflation relies largely on people's forward inflation expectations - highlighting the role of properly anchoring inflation expectations. The only other source of persistence would then emanate from marginal cost - persistence in marginal cost would lead to persistence in inflation.

Although Burger's (2014) study focuses on the link between uncertainty and inflation, an addition outcome of his analysis is inflation persistence during high and low market uncertainty. 
Burger (2014) uses two methods in his study: a general to specific methodology as advocated by Doornik (2009) and Hamilton's (1989, 1996) Markov-switching model. The regressions control for a number of factors such as exchange rate pass-through, market uncertainty, demand shocks and inflation inertia. Inflation persistence is measured in a similar fashion as Rangasamy (2009) and equals the sum of the coefficients of different lagged inflation. Inflation persistence varies between 0.50 and 0.74 depending on the regime and specification. Inflation persistence is highest in the market uncertainty regime and lowest during tranquil market conditions.

An interesting paper by Burger and Marinkov (2008) obtain recursive estimates for inflation persistence pre and post inflation targeting. They show that inflation persistence has not decreased since inflation targeting (but is mean reverting none the less) and doubt whether the SARB is able to decrease inflation persistence at all with the new monetary policy regime. They conclude, however, that the SARB is able to anchor expectations. This suggests that the link between persistent inflation and inflation expectations are not clear - thus even with a credible monetary policy regime inflation is still very persistent and possible close to a unit root.

In a paper critical to inflation targeting in South Africa, Faul et al. (2014) estimate inflation persistence for three thresholds - the inflation target band of 3\%-6\%, a very low inflation threshold of less than $3 \%$ and a high inflation threshold of more than $6 \%$. They use monthly inflation data from 2003 until 2014 thus encompassing only the inflation period. It is unsurprising that they find that inflation is mostly persistent between $3 \%-6 \%$. This could imply that inflation expectations are well anchored. However, the sum of the lagged inflation parameter is larger than unity - which should imply an explosive inflation path - not a return to the target range. They seem to argue that inflation becomes explosive when it it falls within this range thus implying that the SARB's target is not valid. In contrast, the high inflation regime has a mean reverting property. Unfortunately the results do not tell us what the mean reverting inflation level is since the thresholds have been arbitrarily chosen. What is surprising is that that they suggest that the SARB revise the inflation target upwards or altogether abandon inflation targeting without studying the economic impact of such a change. More interestingly, they show that inflation is also mean reverting for a threshold lower than the lower target - but do not advocate a lower policy target for the SARB. It is a rather big leap to infer what the SARB should do with its inflation target given the persistence of inflation. As mentioned earlier, persistence varies by regime, by volatility and by time varying levels. The sample data used in the Faul et al. (2014) paper is very short and only covers one specific regime. Furthermore, the fact that the sum of lagged inflation coefficients is only slightly higher than unity could suggest that inflation might be close to a unit root and in fact not exceed it if the appropriate time span and model is chosen. This is substantiated by the analysis of Gil-Alana (2011) who uses a fractionally integrated model of inflation - inflation is close to a unit root, but is still mean reverting. 


\section{Data}

We use monthly data on headline Consumer Price Index (CPI) and core CPI, which is headline CPI excluding food and energy prices, covering the period of 1975:1 until 2015:4, with the start and end dates being purely driven by data availability. The headline inflation and the core inflation rates are calculated as the log difference between two subsequent months. We use core inflation to control for the possibility that volatility might bias our results (Manzan and Zerom, 2015). The data is sourced from Statistics South Africa. Since we lose the first observation while computing inflation rates, we have a total of 483 observations to work with.

\section{Methodology}

\subsection{Quantile unit root}

We use the novel unit root test developed by Koenker and Xiao's (2004) to test the mean reverting properties of inflation in a quantile regression framework. The test is an extension of Dickey- Fuller type unit root test with higher power when a variable has heavy-tails. Another advantage of the test is that it allows for a different adjustment mechanism towards the long-run equilibrium at different quantiles.

To illustrate the test, we start with following specification of augmented Dickey-Fuller unit root test (ADF hereafter):

$\pi_{t}=\alpha_{0}+\rho_{1} \pi_{t-1}+\sum_{\mathrm{k}=1}^{\mathrm{k}=1} \rho_{1+k} \Delta \pi_{t-k}+\varepsilon_{\mathrm{t}}$

Where stochastic variable $\left\{\pi_{t}\right\}_{t=1}^{T}$ is the inflation rate, $\alpha_{0}$ is intercept and $\varepsilon_{\mathrm{t}}$ is independent and identically (i.i.d) innovation with mean zero and variance $\sigma^{2}$. To control for autocorrelation we include $\sum_{\mathrm{k}=1}^{\mathrm{k}=1} \rho_{1+k} \Delta \pi_{t-k}$ to avoid autocorrelation with the error term.$\rho_{1}$ is the AR coefficient and reflects the degree of persistence. $\left|\rho_{1}\right|<1$ suggests that the series is mean reverting thus ruling out explosive behavior. If $\left|\rho_{1}\right|=1$, it suggests that inflation rate series follows a unit root process. Koenker and Xiao (2004) define the $\tau_{\text {th }}$ conditional quantile of $\pi_{t}$ as follows:

$Q_{\pi_{\mathrm{t}}}\left(\tau \mid \xi_{t-1}\right)=\alpha_{0}(\tau)+\rho_{1}(\tau) \pi_{t-1}+\sum_{\mathrm{k}=1}^{\mathrm{k}=1} \rho_{1+k}(\tau) \Delta \pi_{t-k}$

Where $\mathrm{Q}_{\pi_{\mathrm{t}}}\left(\tau \mid \xi_{\mathrm{t}-1}\right)$ is $\tau_{\mathrm{th}}$ quantile of $\pi_{\mathrm{t}}$ conditional on the past information set, $\xi_{\mathrm{t}-1} \cdot \alpha_{0}(\tau)$ is $\tau_{\text {th }}$ conditional quantile of $\varepsilon_{\mathrm{t}}$. As noted by Tsong and Lee (2011), the estimated values capture the magnitude of inflation rate shock in each quantile. $\rho_{1}(\tau)$ measures the speed of mean reversion of $\pi_{t}$ within each quantile. Also, using $\rho_{1}(\tau)$, we can measure the persistence of a 
shock to inflation rate series through the half lives in each quantile, which is formulated as $\ln (0.5) / \ln \left(\hat{\rho}_{1}(\tau)\right.$. We determine the optimum $\operatorname{lag}(\mathrm{s}), \mathrm{k}$, using AIC information criteria.

The coefficients $\alpha_{0}(\tau), \rho_{1}(\tau)$, and $\rho_{2}(\tau), \ldots, \rho_{\mathrm{k}+1}(\tau)$ are estimated by minimizing sum of asymmetrically weighted absolute deviations.

To decide about unit root behavior over a range of quantiles, Koenker and Xiao (2004) recommend using the quantile Kolmogorov-Smirnov (QKS) test:

$Q K S=\sup _{\tau_{\mathrm{i}} \in[\underline{\lambda}, \bar{\lambda}]}\left|\mathrm{t}_{\mathrm{n}}(\tau)\right|$

In this paper, we construct the QKS statistics by choosing maximum $\left|t_{n}(\tau)\right|$ statistics over range $\tau_{\mathrm{i}} \in[0.1,0.9]$. As noted by Koenker and Xiao (2004), the limiting distributions of $\mathrm{t}_{\mathrm{n}}\left(\tau_{\mathrm{i}}\right)$ and $Q K S$ test statistics are nonstandard and depend on nuisance parameters. Hence To derive critical values for the above mentioned tests, we implement the re-sampling procedures of Koenker and Xiao (2004) as follows:

1- We run following 1-order autoregression by ordinary least square:

$\Delta \pi_{t}=\sum_{\mathrm{k}=1}^{\mathrm{k}=\mathrm{l}} \rho_{k} \Delta \pi_{t-k}+\epsilon_{\mathrm{t}}$

2- Save fitted values $\Delta \hat{\pi}_{t}=\sum_{\mathrm{k}=1}^{\mathrm{k}=1} \hat{\rho}_{k} \Delta \hat{\pi}_{t-k}$ and residuals $\hat{\epsilon}_{\mathrm{t}}$, and then create bootstrap residuals $\left(\epsilon_{\mathrm{t}}^{\mathrm{b}}\right)$ with replacement from the centered residuals $\hat{\epsilon}_{\mathrm{t}}=\hat{\epsilon}_{\mathrm{t}}-\frac{1}{\mathrm{n}-1} \sum_{\mathrm{t}=1+1}^{\mathrm{n}} \hat{\epsilon}_{\mathrm{t}}$.

3- Calculate the bootstrap sample of observations $\pi_{\mathrm{t}}^{\mathrm{b}}$ as follows:

$\pi_{\mathrm{t}}^{\mathrm{b}}=\pi_{\mathrm{t}-1}^{\mathrm{b}}+\Delta \pi_{\mathrm{t}}^{\mathrm{b}}$

With $\left\{\begin{array}{l}\Delta \pi_{\mathrm{t}}^{\mathrm{b}}=\sum_{\mathrm{k}=1}^{\mathrm{k}=\mathrm{l}} \hat{\rho}_{k} \Delta \pi_{\mathrm{t}-\mathrm{k}}^{\mathrm{b}}+\epsilon_{\mathrm{t}}^{\mathrm{b}} ; \\ \Delta \pi_{\mathrm{j}}^{\mathrm{b}}=\Delta \pi_{\mathrm{j}} \text { for } \mathrm{j}=1,2, \ldots, \mathrm{l} ; \\ \pi_{1}^{\mathrm{b}}=\pi_{1} ;\end{array}\right.$

We construct the $\alpha_{0}(\tau)$ and $\rho_{1}(\tau)$ based on equation (2), statistics based on and QKS statistics based on equations. (4).

4- We repeat steps 2 and 3500 times and the collection of realized $t_{n}(\tau)$ and QKS statistics provides us an approximation to the cumulative distribution functions of them. Also, to construct the $95 \%$ confidence intervals for the $\alpha_{0}(\tau)$ and $\rho_{1}(\tau)$, we use their empirical distribution functions. 


\subsection{Breaks in the persistence}

South Africa adopted an inflation targeting policy from 2000. As a consequence it is possible that inflation has some breaks in persistence. To test this hypothesis, we examine changes in inflation persistence using the Oka and Qu (2011) test that allows for structural change in multiple conditional quantiles and with unknown timing in dynamic regression quantiles including quantile autoregression.

The conditional quantile of $\pi_{t}$ with $m$ unknown structural breaks is written as:

$Q_{\pi_{\mathrm{t}}}\left(\tau \mid \xi_{t-1}\right)=$

$$
\left\{\begin{array}{c}
\alpha_{0,1}(\tau)+\rho_{1,1}(\tau) \pi_{t-1}+\sum_{\mathrm{k}=1}^{\mathrm{k}=1} \rho_{1+k, 1}(\tau) \Delta \pi_{t-k}, \quad \mathrm{t}=1,2, \ldots, \mathrm{T}_{1}^{0} \\
\alpha_{0,2}(\tau)+\rho_{1,2}(\tau) \pi_{t-1}+\sum_{\mathrm{k}=1}^{\mathrm{k}=1} \rho_{1+k, 2}(\tau) \Delta \pi_{t-k}, \quad \mathrm{t}=\mathrm{T}_{1}^{0}+1, \mathrm{~T}_{1}^{0}+2, \ldots, \mathrm{T}_{2}^{0} \\
\vdots \\
\alpha_{0, m+1}(\tau)+\rho_{1, m+1}(\tau) \pi_{t-1}+\sum_{\mathrm{k}=1}^{\mathrm{k}=1} \rho_{1+k, m+1}(\tau) \Delta \pi_{t-k},
\end{array}\right.
$$

Where $\alpha_{0, j}, \rho_{1, j}$, and $\rho_{1+k, j}$ are unknown parameters that are quantile dependent and $\mathrm{T}_{\mathrm{j}}^{0}(\mathrm{j}=$ $1,2, \ldots, \mathrm{m})$ are unknown break dates. The test is run in the two steps. In the first step, we test the existence of structural break across a range of quantiles by using DQ test and determine the number and location of breaks simultaneously ${ }^{1}$.

If the DQ-test rejects the null hypothesis of no structural break, in the second step, we test the structural stability in the pre-specified quintiles using the $S Q_{\tau}$ test ${ }^{2}$.

We detect the number of structural breaks by estimating the persistence parameters for the different quantiles under the null of no structural breaks. We proceed then to estimate the quantiles separately for different sub-samples based on the previous break date. If the null hypothesis of no structural change is rejected, we test in sequential steps the null hypothesis of 1 break against the alternative hypothesis of 2 breaks using the DQ(1+1|1)- and the SQ $\mathrm{C}_{\tau}(1+1 \mid 1)$ tests. If we find evidence in favor of 2 breaks we check the null hypothesis of 2 breaks against

\footnotetext{
1 . The hypothesis for DQ test is as:

H0: $\alpha_{0, j}(\tau)=\alpha_{0}(\tau), \rho_{1, j}(\tau)=\rho_{1}(\tau), \rho_{1+k, j}(\tau)=\rho_{1+k}(\tau)$, for all $\mathrm{j}$ and for all $\mathrm{D} \in\{0.1,0.2$, and for

$\mathrm{H} 1:\left\{\begin{array}{c}\alpha_{0, j}(\tau)=\alpha_{0,1}(\tau), \rho_{1, j}(\tau)=\rho_{1,1}(\tau), \rho_{1+k, j}(\tau)=\rho_{1+k, 1}(\tau), \text { for } \mathrm{t}=1,2, \text { an } t_{0} \\ \alpha_{0, j}(\tau)=\alpha_{0,2}(\tau), \rho_{1, j}(\tau)=\rho_{1,2}(\tau), \rho_{1+k, j}(\tau)=\rho_{1+k, s}(\tau), \text { for } \mathrm{t}=t_{0}+1, t_{0}+2, \mathrm{t}=\end{array} \quad\right.$ for some $\tau \in$

$\{0.1,0.2, \mathrm{r}$ some

2 . The hypothesis for $\mathrm{SQ}_{\tau}$ test is as:

H0: $\alpha_{0, j}(\tau)=\alpha_{0}(\tau), \rho_{1, j}(\tau)=\rho_{1}(\tau), \rho_{1+k, j}(\tau)=\rho_{1+k}(\tau)$, for all $\mathrm{j}$ and for a given $\mathrm{e} \in\{0.1,0.2$, and for

$\mathrm{H} 1:\left\{\begin{array}{c}\alpha_{0, j}(\tau)=\alpha_{0,1}(\tau), \rho_{1, j}(\tau)=\rho_{1,1}(\tau), \rho_{1+k, j}(\tau)=\rho_{1+k, 1}(\tau), \text { for } \mathrm{t}=1,2, \text { ant } t_{0} \\ \alpha_{0, j}(\tau)=\alpha_{0,2}(\tau), \rho_{1, j}(\tau)=\rho_{1,2}(\tau), \rho_{1+k, j}(\tau)=\rho_{1+k, s}(\tau), \text { for } \mathrm{t}=t_{0}+1, t_{0}+2, \mathrm{t}=\end{array}\right.$
} 
the alternative hypothesis of 3 breaks and so on (see Tillman and Wolters (2015) for an exact exposition). Tables for critical values are provided in $\mathrm{Qu}$ (2008).

\section{Empirical results}

Inflation has large tails. A simple density plot (Figure 1) and a Q-Q plot (Figure 2) show that inflation has a large weight on the right tail of the distribution. We use this result to motivate our use of a quantile regression approach.

We break the quantile unit root test into various periods as determined by structural break test from Oka and $\mathrm{Qu}$ (2011), and also to account for the inflation targeting regime that was adopted by the South African Reserve Bank (SARB) in the year 2000. We test the unit root behaviour for inflation quantiles using i.) the full sample period: 1975:02-2015:04, ii.) 1975:02-1992:04, iii.) 1992:05-2015:04, iv.) 1975:02-1999:12 and iv.) 2000:01-2015:04. Our structural break test revealed a break only in in 1992:04 for both the headline and core inflation rates. In an excellent survey, Aron and Muellbauer (2006) provide a breakdown of South Africa's monetary policy stance since the 1970's. Some of our structural dates fall within these changes. In 1991 the monetary policy stance was supplemented by an eclectic range of indicators, while the periods between 1996 and 1998 monetary policy had costly economic consequences and saw the introduction of the repo rate being market determined through repurchase transactions.

The quantile unit root test for the entire sample (Table 1), 1975:02-2015:04, shows that inflation is a stationary process for headline inflation in quantiles 1 to 9 , but is significant only for quantiles 1 to 5 . Core inflation is stationary for quantiles 1 to 6 but also only significant for the first five quantiles. The half-life for the median quantile is 2.4 periods and 4 periods respectively for headline and core inflation.

The opposite is true for the period 1975:02-1992:04 (Table 2). Inflation persistence is above unity for the first two quantiles and mean-reverting for the following eight. Surprisingly the highest quantiles show the least amount of persistence for both headline and core inflation. The results are only statistically significant for the inner quantiles. Inflation persistence is quite low for the period 1992:05-2015:04 (Table 3) except for the last quantile, which is near the unit interval and is insignificant. The quantile unit root test for the period 1975:02-1999:12 shows that headline inflation is persistent and even explosive in the first few quantiles. Core inflation during this sample is stationary but very persistent. None of the results are significant. With benefit in hindsight, a researcher that used the exact same test in 1999 might then have had conclude that inflation was explosive and that the monetary policy tools used over that period was inefficient and not able to stabilise prices. 
In contrast to previous regimes, headline inflation is mostly mean reverting for quantiles 1-9 during 2000:01-2015:04 (Table 5) while very constant for core inflation in all quantiles and exhibits low persistence. This is a departure from the preceding paragraph regarding monetary policy before inflation targeting. The results, over this period, suggest that particular policies such as credible inflation targeting has the ability to staibilise prices

As expected, the intercepts in Figure 3 to 7 are increasing in the quantile ranges over the different sub samples. The figures also show how sensitive the results are to the sample chosen. For the entire sample (Figure 3) inflation persistence is increasing in quantile range for both headline and core inflation. The last quantile coefficient reaches unity while the rest is below one. Inflation persistence is not equal between different levels of inflation - high inflation is much more persistent - and can be explosive, which is in line with Balcilar et al. (2015).

The results are reversed when studying inflation persistence for the period 1975:02-1992:04 (see Figure 4): Persistence declines as inflation moves from the first to the median quantile, although most of the quantile estimates are insignificant. Core and headline inflation persistence increases then slightly from the median quantile to the last quantile, but is once again insignificant.

Expanding the previous sample by seven years, 1975:02-1999:12, leads to markedly different results. This shows how sensitive persistence estimates are to structural breaks as well as sample periods. Both headline and core inflation during this period is remarkably persistent across all quantiles. The standard errors are wide implying that the results are not significant.

The inflation targeting period (Figure 7) from 2000:01-2015:04 shows that persistence also increases as one moves up in the quantile range for headline inflation. More interestingly, inflation persistence increases considerably moving from the median quantile to higher quantiles. Core inflation, however, has an equal persistence across all quantiles and moves between 0.3 and 0.6, which is low and in line with the estimates that Burger (2014) obtained. Only in this period do we observe a marked difference between headline and core inflation estimates across the quantile range, which leads to some validity that not accounting for inflation volatility leads to biased and higher inflation persistence estimates - recall that Burger (2014) controls for uncertainty in the inflation equation by including the VIX index.

The results show that only the period during the inflation targeting regime has a constant persistence estimate for core inflation. Energy and food prices increases the persistence estimates for all quantiles (headline is higher than core). While this does not prove that energy and food price shocks change the underlying distribution of inflation persistence - it does point to a monetary policy conundrum. Energy and food price shocks are often exogenous and not in the control of monetary policy. A large enough energy or food price shock can push inflation to a "dangerous" level where persistence negates policy - to a point where policy becomes ineffective or so severe that it has adverse economic consequences. 
Other periods, which include different monetary policy instruments, ran the risk of run-away inflation as soon as inflation reaches high levels irrespective of the measure of inflation. Persistence is an increasing function in quantiles for headline inflation. Volatility in headline inflation, or the inclusion of various asset prices in inflation might reinforce, or cause bubbles when inflation starts trickling up.

There seems to be clear benefits in keeping inflation low. Inflation targeting has not only decreased the volatility of inflation, but has also kept inflation within levels that limits an explosive inflation path.

It is also interesting to note, that decreases in inflation, since inflation targeting, usually occurs from low inflation levels. Hardly do we notice a decrease in inflation from a high level. This result sheds light on price rigidities and indicates that prices are downward sticky when inflation is high. The consensus from the South African literature, with the exception of one study that we could find, all point to the benefits of inflation targeting. We refrain from discussing the costs of keeping inflation low, although the economy-wide benefits have been well recorded. If the SARB's objective continues to maintain stable prices it will do well to keep the inflation targeting framework or perhaps even target lower inflation as opposed to reverting back to using previous tools.

\section{Conclusion}

This paper studies the persistence of inflation, both headline and core, for the South African economy. This paper is the first to study inflation persistence using quantile regressions for the country. The size of inflation persistence for various quantiles varies across different monetary policy regimes. Persistence in the top quantiles is close to a unit root, and in some cases exhibit unit root behaviour. The consequence is clear - if inflation is unchecked and allowed to increase then monetary policy will find it very hard to stabilise prices at some desirable level. The results, however, show that persistence of core inflation for all quantiles since inflation targeting has been constant and low. The implications are that monetary policy has been able to anchor inflation expectations even when inflation breaches the upper limit in the target. The commitment to inflation targeting suggests that inflation will return to its mean if there are short run shocks which cause a considerable deviation from the target range.

\section{References}


Amisano, G. and Tristani, O. (2007). "Euro Area inflation persistence in an estimated nonlinear DSGE model", Journal of Economic Dynamics and Control, 34(10), 1837-1858.

Aron, J. and Muellbauer, J. (2006). "Review of monetary policy in South Africa since 1994", CSAE WPS/2006-07.

Balcilar, M., Gupta, R. and Jooste, C. (2015). "Analyzing South Africa's inflation persistence using and ARFIMA model with Markov-switching differencing parameter", Forthcoming in Journal of Developing Areas.

Ball, L. and Mankiw, N.G. (1994). "Asymmetric price adjustment and economic fluctuations", The Economic Journal 104, 247-261.

Batini, N. (2002). "Euro area in inflation persistence", Working paper series 201, European Central Bank .

Batini, N. and Nelson, E. (2001). "The lag from monetary policy actions to inflation: Friedman revisited", International Finance, 4(3), 381-400.

Burger, P. (2014). "Inflation and market uncertainty in South Africa", South African Journal of Economics, 82(4), 583-602.

Burger, P. and Marinkov, M. (2008). "Inflation targeting and inflation performance in South Africa", TIPS Annual Forum Paper. Online available at: http://www.tips.org.za/files/BurgerMarinkov_Tips.pdf, [Accessed: 18 August 2015].

Burger, R. P., and Du Plessis, S. (2013). "A New Keynesian Phillips curve for South Africa". In P. Schaeffer \& E. Kouassi (Eds.), Econometric methods for analyzing economic development (pp. 30-48). Hershey, Pa.: IGI Global.

Caballero, R.J. and Engel, E.R.M.A. (1993). "Microeconomic rigidities and aggregate price dynamics", European Economic Review 37, 697-717.

Calvo, G.A. (1983). "Staggered prices in a utility maximizing framework", Journal of Monetary Economics, 12, 383-398.

Clark, T. (2006). "Disaggregate evidence on the persistence of consumer price inflation", Journal of Applied Econometrics, 21(5), 563-587. 
Cogley, T. and Sargent, T.J. (2002). "Evolving Post-WWII U.S. Inflation Dynamics", in B. Bernanke and K. Rogoff, eds. (2002), NBER Macroeconomics Annuals 2001. (2005):

Cogley, T. and Sargent, T.J. (2002). "Drifts and Volatilities: Monetary Policies and Outcomes in the Post WWII U.S.”, Review of Economic Dynamics, 8(April), 262-302.

Doornik, J.A. (2009). "Econometric Model Selection With more Variables Than Observations", Working Paper, Economics Department, University of Oxford. Online: http://creates.au.dk/fileadmin/site_files/filer_oekonomi/subsites/creates/Seminar_Papers/2009/ Jurgen_Doornik_051109.pdf.

Faul, J., Khumalu, B., Mpho, P., Miranda, K., Kamogelo, B., Senzo, J., Bathandekile, M., Retlaodirelam, P., Boitshoko, M., Lona-u-Thando, J. and Phiri, A. (2014). "Is South Africa's inflation target too persistent for monetary policy conduct?", MPRA Paper Number 58233.

Fuhrere, J.C. (2011). "Inflation persistence", in B. Friedman and M. Woodford (eds.), Handbook of Monetary Economics, Volume 3A, Elsevier, North Holland.

Gil-Alana, L.A. (2011), "Inflation in South Africa. A long memory approach", Economics Letters, 111(3), 207-209.

Hamilton, J.D. (1996). "Specification testing in Markov-switching time-series models", Journal of Econometrics, 70: 127-57.

Hamilton, J.D. (1989). "A new approach to the econometric analysis of nonstationary timeseries and the business cycle", Journal of Econometrics, 57(2): 357-84.

Jarque, C. M. and Bera, A. K. (1980). "Efficient tests for normality, Heteroscedasticity and Serial Independence of Regression Residuals", Economic Letters, 6, 255-259.

Manzan, S. and Zerom, D. (2015). "Asymmetric quantile persistence and predictability: The case of US inflation", Oxford Bulletin of Economics and Statistics, 77(2), 297-318.

Koenker, R. and Xiao, Z. (2004). "Unit root quantile autoregression inference",Journal of the American Statistical Association 99, 775-787.

Laxton, D., Rose, D. and Tambakis, D. (1999). "The U.S. Phillips curve: The case for asymmetry", Journal of Economic Dynamics and Control, 23(1999), 1459-1485. 
Levin, A. T. and Piger, J. M. (2004). "Is inflation persistence intrinsic in industrial economies?", Working paper series 334, European Central Bank.

Oka, T. and Z. Qu. (2011). "Estimating structural changes in regression quantiles", Journal of Econometrics 162, 248-276.

Pivetta, F. and Reis, R. (2007). "The persistence of inflation in the united states", Journal of Economics, Dynamics and Control, 31(4), 1326-1358.

Rangasamy, L.( 2009). "Inflation Persistence and Core Inflation: The Case of South Africa", South African Journal of Economics, 77(3), 430-444.

Stock, J.H. (2002). "Comment on: Evolving post-world war II U.S. inflation dynamics", In NBER

Macroeconomics Annual 2001 (eds B.S. Bernanke and K. Rogoff). MIT Press.

Tillman and Wolters (2012). "The changing dynamics of US inflation persistence: a quantile regression approach", Studies in Nonlinear Dynamics \& Econometrics, 19(2), 161-182.

Tsong, C. and Lee, F. (2011). "Asymmetric inflation dynamics: Evidence from quantile regression analysis" Journal of Macroeconomics, 3(2011), 668-680. 
Table 1: Quantile unit root test results for period 1975:02-2015:04

\begin{tabular}{|c|c|c|c|c|c|c|c|c|c|c|}
\hline & Quantiles & 0.1 & 0.2 & 0.3 & 0.4 & 0.5 & 0.6 & 0.7 & 0.8 & 0.9 \\
\hline \multirow{9}{*}{ Inflation } & $\alpha_{0}(\tau)$ & $\begin{array}{l}- \\
0.655\end{array}$ & $\begin{array}{l}- \\
0.434\end{array}$ & $\begin{array}{l}- \\
0.289\end{array}$ & $\begin{array}{l}- \\
0.176\end{array}$ & $\begin{array}{l}- \\
0.067\end{array}$ & 0.071 & 0.212 & 0.405 & 0.659 \\
\hline & $p$-Value & 0.000 & 0.000 & 0.000 & 0.000 & 0.031 & 0.034 & 0.000 & 0.000 & 0.000 \\
\hline & $\rho_{1}(\tau)$ & 0.528 & 0.706 & 0.662 & 0.682 & 0.756 & 0.861 & 0.914 & 0.988 & 1.081 \\
\hline & $p$-value & 0.000 & 0.002 & 0.000 & 0.000 & 0.007 & 0.119 & 0.228 & 0.464 & 0.323 \\
\hline & Half live & 1.085 & 1.991 & 1.680 & 1.811 & 2.478 & $\infty$ & $\infty$ & $\infty$ & $\infty$ \\
\hline & & - & - & - & - & - & - & - & - & ק \\
\hline & $t_{n}\left(\tau_{i}\right)$ & 3.797 & 2.888 & 4.072 & 3.754 & 2.916 & 1.395 & 0.806 & 0.101 & $0.3 / 3$ \\
\hline & $p$-value & 0.000 & 0.008 & 0.002 & 0.000 & 0.020 & 0.374 & 0.668 & 0.858 & 0.940 \\
\hline & $\begin{array}{l}\text { QKS } \\
\text { statistics }\end{array}$ & 4.072[ & CV10\% & 3.062 & CV $5 \%=$ & 40 & $\mathrm{CV} 1 \%=$ & .819] & & \\
\hline \multirow{9}{*}{$\begin{array}{l}\text { Core } \\
\text { inflation }\end{array}$} & $\alpha_{0}(\tau)$ & $\begin{array}{l}- \\
0.611\end{array}$ & $\begin{array}{l}- \\
0.404\end{array}$ & $\begin{array}{l}- \\
0.316\end{array}$ & $\begin{array}{l}- \\
0.188\end{array}$ & $\begin{array}{l}- \\
0.056\end{array}$ & 0.052 & 0.220 & 0.447 & 0.697 \\
\hline & $p$-Value & 0.000 & 0.000 & 0.000 & 0.000 & 0.069 & 0.107 & 0.000 & 0.000 & 0.000 \\
\hline & $\rho_{1}(\tau)$ & 0.412 & 0.593 & 0.666 & 0.729 & 0.849 & 0.893 & 1.053 & 1.102 & 1.217 \\
\hline & $p$-value & 0.000 & 0.000 & 0.000 & 0.003 & 0.089 & 0.186 & 0.365 & 0.275 & 0.138 \\
\hline & Half live & 0.782 & 1.326 & 1.705 & 2.193 & 4.234 & $\infty$ & $\infty$ & $\infty$ & $\infty$ \\
\hline & $t(\tau)$ & - & - & 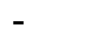 & - & - & - & 0.470 & 0774 & 1097 \\
\hline & $l_{n}(2 \mathrm{i})$ & 4.042 & 4.893 & 3.927 & 3.579 & 1.693 & 1.005 & $0.4 / 0$ & $0.1 / 4$ & 1.091 \\
\hline & $p$-value & 0.002 & 0.000 & 0.000 & 0.000 & 0.160 & 0.530 & 0.942 & 0.986 & 0.998 \\
\hline & $\begin{array}{l}\text { QKS } \\
\text { statistics }\end{array}$ & \multicolumn{9}{|c|}{$4.893[\mathrm{CV} 10 \%=2.916$} \\
\hline
\end{tabular}

Notes: 1)The figures in the parenthesis are $p$-value. 2) The $p$-values for $t_{n}\left(\tau_{i}\right)$ and QKS statistics computed using bootstrapping procedure and 500 replications. 3) For quantiles which $\rho_{1}(\tau)$ is greater than unit, the half live is equal to $\infty$. 
Table 2: Quantile unit root test results for period 1975:02-1992:04

\begin{tabular}{|c|c|c|c|c|c|c|c|c|c|c|}
\hline & Quantiles & 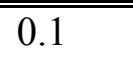 & 0.2 & 0.3 & 0.4 & 0.5 & 0.6 & 0.7 & 0.8 & 0.9 \\
\hline \multirow{8}{*}{ Inflation } & $\alpha_{0}(\tau)$ & -0.743 & -0.508 & -0.341 & -0.145 & -0.014 & 0.150 & 0.223 & 0.467 & 0.760 \\
\hline & $p$-Value & 0.000 & 0.000 & 0.000 & 0.005 & 0.404 & 0.007 & 0.000 & 0.000 & 0.000 \\
\hline & $\rho_{1}(\tau)$ & 1.159 & 1.017 & 0.612 & 0.294 & 0.176 & $\begin{array}{l}- \\
0.007\end{array}$ & 0.040 & 0.164 & 0.243 \\
\hline & $p$-value & 0.362 & 0.483 & 0.150 & 0.016 & 0.009 & 0.002 & 0.008 & 0.022 & 0.144 \\
\hline & Half live & $\infty$ & $\infty$ & 1.412 & 0.566 & 0.399 & NA & 0.215 & 0.383 & 0.490 \\
\hline & $t_{n}\left(\tau_{i}\right)$ & 0.382 & 0.050 & -1.169 & -2.110 & -2.663 & $\begin{array}{l}- \\
3.200\end{array}$ & -2.984 & -1.337 & -0.859 \\
\hline & $p$-value & 0.890 & 0.850 & 0.430 & 0.116 & 0.018 & 0.008 & 0.014 & 0.260 & 0.416 \\
\hline & $\begin{array}{l}\text { QKS } \\
\text { statistics }\end{array}$ & \multicolumn{4}{|c|}{$3.200[\mathrm{CV} 10 \%=3.036 \mathrm{CV} 5 \%=3.256$} & $\mathrm{CV} 1 \%=$ & 761] & & & \\
\hline \multirow{8}{*}{$\begin{array}{l}\text { Core } \\
\text { Inflation }\end{array}$} & $\alpha_{0}(\tau)$ & -0.723 & -0.588 & -0.389 & -0.180 & -0.027 & 0.132 & 0.273 & 0.472 & 0.825 \\
\hline & $p$-Value & 0.000 & 0.000 & 0.000 & 0.005 & 0.358 & 0.021 & 0.000 & 0.000 & 0.000 \\
\hline & $\rho_{1}(\tau)$ & 1.318 & 1.242 & 0.883 & 0.279 & 0.182 & $\begin{array}{l}- \\
0.029\end{array}$ & -0.192 & 0.217 & 0.126 \\
\hline & $p$-value & 0.287 & 0.300 & 0.397 & 0.043 & 0.023 & 0.005 & 0.008 & 0.064 & 0.122 \\
\hline & Half live & $\infty$ & $\infty$ & 5.571 & 0.543 & 0.407 & NA & NA & 0.454 & 0.335 \\
\hline & $t_{n}\left(\tau_{i}\right)$ & 0.634 & 0.798 & -0.335 & -1.746 & -2.270 & $\begin{array}{l}- \\
2.931\end{array}$ & -2.790 & -1.563 & -0.986 \\
\hline & $p$-value & 0.962 & 0.970 & 0.818 & 0.238 & 0.100 & 0.020 & 0.008 & 0.198 & 0.432 \\
\hline & $\begin{array}{l}\text { QKS } \\
\text { statistics }\end{array}$ & \multicolumn{4}{|c|}{$2.931[\mathrm{CV} 10 \%=3.097 \mathrm{CV} 5 \%=3.301$} & $\mathrm{CV} 1 \%=$ & & & & \\
\hline
\end{tabular}

Notes: See Notes to Table 1. 
Table 3: Quantile unit root test results for period 1992:05-2015:04

\begin{tabular}{|c|c|c|c|c|c|c|c|c|c|c|}
\hline & Q Quantiles & 0.1 & $\overline{0.2}$ & 0.3 & 0.4 & 0.5 & 0.6 & 0.7 & 0.8 & $\overline{0.9}$ \\
\hline \multirow{9}{*}{ Inflation } & $\alpha_{0}(\tau)$ & $\begin{array}{l}- \\
0.487\end{array}$ & $\begin{array}{l}- \\
0.350\end{array}$ & 0.208 & $\begin{array}{l}- \\
0.126\end{array}$ & $\begin{array}{l}- \\
0.053\end{array}$ & 0.049 & 0.153 & 0.322 & 0.567 \\
\hline & $p$-Value & 0.000 & 0.000 & 0.000 & 0.000 & 0.040 & 0.061 & 0.000 & 0.000 & 0.000 \\
\hline & $\rho_{1}(\tau)$ & 0.371 & 0.226 & 0.236 & 0.395 & 0.417 & 0.470 & 0.578 & 0.617 & 0.890 \\
\hline & $p$-value & 0.000 & 0.000 & 0.000 & 0.000 & 0.000 & 0.001 & 0.015 & 0.039 & 0.344 \\
\hline & Half live & 0.699 & 0.466 & 0.480 & 0.746 & 0.792 & 0.918 & 1.264 & 1.435 & 5.948 \\
\hline & \multirow{2}{*}{$t_{n}\left(\tau_{i}\right)$} & - & - & - & - & - & - & - & - & - \\
\hline & & 3.524 & 4.487 & 5.032 & 4.147 & 4.050 & 3.120 & 2.422 & 1.566 & 0.398 \\
\hline & \multirow{2}{*}{$\begin{array}{l}p \text {-value } \\
\text { QKS } \\
\text { statistics }\end{array}$} & 0.004 & 0.000 & 0.000 & 0.000 & 0.000 & 0.018 & 0.056 & 0.252 & 0.694 \\
\hline & & \multicolumn{9}{|c|}{$5.032[\mathrm{CV} 10 \%=3.112 \mathrm{CV} 5 \%=3.411 \mathrm{CV} 1 \%=4.049]$} \\
\hline \multirow{9}{*}{$\begin{array}{l}\text { Core } \\
\text { Inflation }\end{array}$} & $\alpha_{0}(\tau)$ & $-\overline{0}-466$ & $-\overline{0}-303$ & $\begin{array}{l}- \\
0.226\end{array}$ & $\overline{-}-150$ & $-\overline{0}-077$ & 0.040 & 0.137 & 0.307 & 0.510 \\
\hline & $p$-Value & 0.000 & 0.000 & 0.000 & 0.000 & 0.002 & 0.112 & 0.000 & 0.000 & 0.000 \\
\hline & $\rho_{1}(\tau)$ & 0.637 & 0.370 & 0.371 & 0.404 & 0.398 & 0.337 & 0.299 & 0.621 & 0.755 \\
\hline & $p$-value & 0.058 & 0.000 & 0.000 & 0.000 & 0.000 & 0.000 & 0.000 & 0.025 & 0.163 \\
\hline & Half live & 1.537 & 0.697 & 0.699 & 0.765 & 0.752 & 0.637 & 0.574 & 1.455 & 2.466 \\
\hline & \multirow{2}{*}{$t_{n}\left(\tau_{i}\right)$} & - & - & - & - & - & - & - & - & - \\
\hline & & 1.585 & 4.125 & 6.159 & 4.853 & 4.608 & 4.221 & 3.630 & 1.717 & 0.924 \\
\hline & $p$-value & 0.110 & 0.002 & 0.000 & 0.000 & 0.000 & 0.000 & 0.008 & 0.208 & 0.438 \\
\hline & $\begin{array}{l}\text { QKS } \\
\text { statistics }\end{array}$ & \multicolumn{9}{|c|}{$6.159[\mathrm{CV} 10 \%=2.979 \mathrm{CV} 5 \%=3.230 \mathrm{CV} 1 \%=3.752]$} \\
\hline
\end{tabular}

Notes: See Notes to Table 1. 
Table 4: Quantile unit root test results for period 1975:02-1999:12

\begin{tabular}{|c|c|c|c|c|c|c|c|c|c|c|}
\hline & Quantiles & 0.1 & 0.2 & 0.3 & 0.4 & 0.5 & 0.6 & 0.7 & 0.8 & 0.9 \\
\hline \multirow{8}{*}{ Inflation } & $\alpha_{0}(\tau)$ & -0.691 & -0.512 & -0.361 & -0.238 & -0.070 & 0.059 & 0.224 & 0.399 & 0.662 \\
\hline & $p$-Value & 0.000 & 0.000 & 0.000 & 0.000 & 0.137 & 0.153 & 0.000 & 0.000 & 0.000 \\
\hline & $\rho_{1}(\tau)$ & 1.103 & 0.993 & 0.816 & 0.791 & 0.747 & 0.871 & 0.831 & 0.746 & 0.859 \\
\hline & $p$-value & 0.307 & 0.482 & 0.112 & 0.115 & 0.079 & 0.244 & 0.202 & 0.123 & 0.333 \\
\hline & Half live & $\infty$ & 98.674 & 3.409 & 2.956 & 2.376 & 5.019 & 3.744 & 2.365 & 4.561 \\
\hline & $t_{n}\left(\tau_{i}\right)$ & 0.482 & -0.045 & -1.139 & -1.242 & -1.492 & -0.731 & -0.948 & -0.990 & -0.291 \\
\hline & $p$-value & 0.912 & 0.806 & 0.422 & 0.404 & 0.340 & 0.660 & 0.554 & 0.492 & 0.726 \\
\hline & $\begin{array}{l}\text { QKS } \\
\text { statistics }\end{array}$ & \multicolumn{9}{|c|}{$1.492[\mathrm{CV} 10 \%=3.018 \mathrm{CV} 5 \%=3.271 \mathrm{CV} 1 \%=3.597]$} \\
\hline \multirow{8}{*}{$\begin{array}{l}\text { Core } \\
\text { Inflation }\end{array}$} & $\alpha_{0}(\tau)$ & -0.767 & -0.531 & -0.383 & -0.233 & -0.079 & 0.054 & 0.224 & 0.462 & 0.763 \\
\hline & $p$-Value & 0.000 & 0.000 & 0.000 & 0.000 & 0.097 & 0.215 & 0.001 & 0.000 & 0.000 \\
\hline & $\rho_{1}(\tau)$ & 0.962 & 0.818 & 0.971 & 0.930 & 0.776 & 0.829 & 0.773 & 0.973 & 0.855 \\
\hline & $p$-value & 0.433 & 0.169 & 0.439 & 0.335 & 0.100 & 0.212 & 0.144 & 0.459 & 0.350 \\
\hline & Half live & 17.892 & 3.450 & 23.553 & 9.551 & 2.733 & 3.696 & 2.692 & 25.324 & 4.425 \\
\hline & $t_{n}\left(\tau_{i}\right)$ & -0.143 & -0.995 & -0.145 & -0.393 & -1.135 & -0.812 & -0.959 & -0.098 & -0.261 \\
\hline & $p$-value & 0.746 & 0.460 & 0.824 & 0.718 & 0.456 & 0.654 & 0.540 & 0.866 & 0.754 \\
\hline & $\begin{array}{l}\text { QKS } \\
\text { statistics }\end{array}$ & \multicolumn{9}{|l|}{1.135} \\
\hline
\end{tabular}

Notes: See Notes to Table 1. 
Table 5: Quantile unit root test results for period 2000:01-2015:12

\begin{tabular}{|c|c|c|c|c|c|c|c|c|c|c|}
\hline & Quantiles & 0.1 & 0.2 & 0.3 & 0.4 & 0.5 & 0.6 & 0.7 & 0.8 & 0.9 \\
\hline \multirow{9}{*}{ Inflation } & $\alpha_{0}(\tau)$ & -0.504 & -0.330 & -0.194 & -0.136 & -0.044 & 0.104 & 0.177 & 0.267 & 0.506 \\
\hline & $p$-Value & 0.000 & 0.000 & 0.000 & 0.000 & 0.121 & 0.009 & 0.000 & 0.000 & 0.000 \\
\hline & $\rho_{1}(\tau)$ & 0.413 & 0.264 & 0.409 & 0.436 & 0.435 & 0.661 & 0.682 & 0.657 & 1.126 \\
\hline & $p$-value & 0.009 & 0.000 & 0.001 & 0.002 & 0.001 & 0.054 & 0.086 & 0.080 & 0.351 \\
\hline & Half live & 0.784 & 0.520 & 0.775 & 0.835 & 0.833 & 1.674 & 1.811 & 1.650 & $\infty$ \\
\hline & $t_{n}\left(\tau_{i}\right)$ & -2.881 & -3.423 & -3.517 & -3.035 & -3.357 & -1.888 & -1.545 & -1.405 & 0.328 \\
\hline & $p$-value & 0.032 & 0.000 & 0.002 & 0.014 & 0.004 & 0.168 & 0.298 & 0.286 & 0.906 \\
\hline & QKS & & & & & & & & & \\
\hline & statistics & \multicolumn{9}{|c|}{$3.517[\mathrm{CV} 10 \%=3.109 \mathrm{CV} 5 \%=3.381 \mathrm{CV} 1 \%=3.874]$} \\
\hline \multirow{9}{*}{$\begin{array}{l}\text { Core } \\
\text { Inflation }\end{array}$} & $\alpha_{0}(\tau)$ & -0.469 & -0.287 & -0.206 & -0.107 & -0.021 & 0.034 & 0.121 & 0.278 & 0.409 \\
\hline & $p$-Value & 0.000 & 0.000 & 0.000 & 0.000 & 0.266 & 0.172 & 0.002 & 0.000 & 0.000 \\
\hline & $\rho_{1}(\tau)$ & 0.571 & 0.511 & 0.343 & 0.348 & 0.437 & 0.407 & 0.492 & 0.267 & 0.451 \\
\hline & $p$-value & 0.083 & 0.008 & 0.000 & 0.000 & 0.002 & 0.001 & 0.015 & 0.003 & 0.037 \\
\hline & Half live & 1.237 & 1.032 & 0.648 & 0.657 & 0.837 & 0.771 & 0.977 & 0.525 & 0.870 \\
\hline & $t_{n}\left(\tau_{i}\right)$ & -2.131 & -2.598 & -3.558 & -4.038 & -3.263 & -3.115 & -2.485 & -3.133 & -2.398 \\
\hline & $p$-value & 0.094 & 0.022 & 0.002 & 0.000 & 0.010 & 0.008 & 0.048 & 0.016 & 0.058 \\
\hline & QKS & & & & & & & & & \\
\hline & statistics & \multicolumn{9}{|c|}{$4.038[\mathrm{CV} 10 \%=3.148 \mathrm{CV} 5 \%=3.391 \mathrm{CV} 1 \%=4.033]$} \\
\hline
\end{tabular}

Notes: See Notes to Table 1. 
Figure 1: Q-Q plot
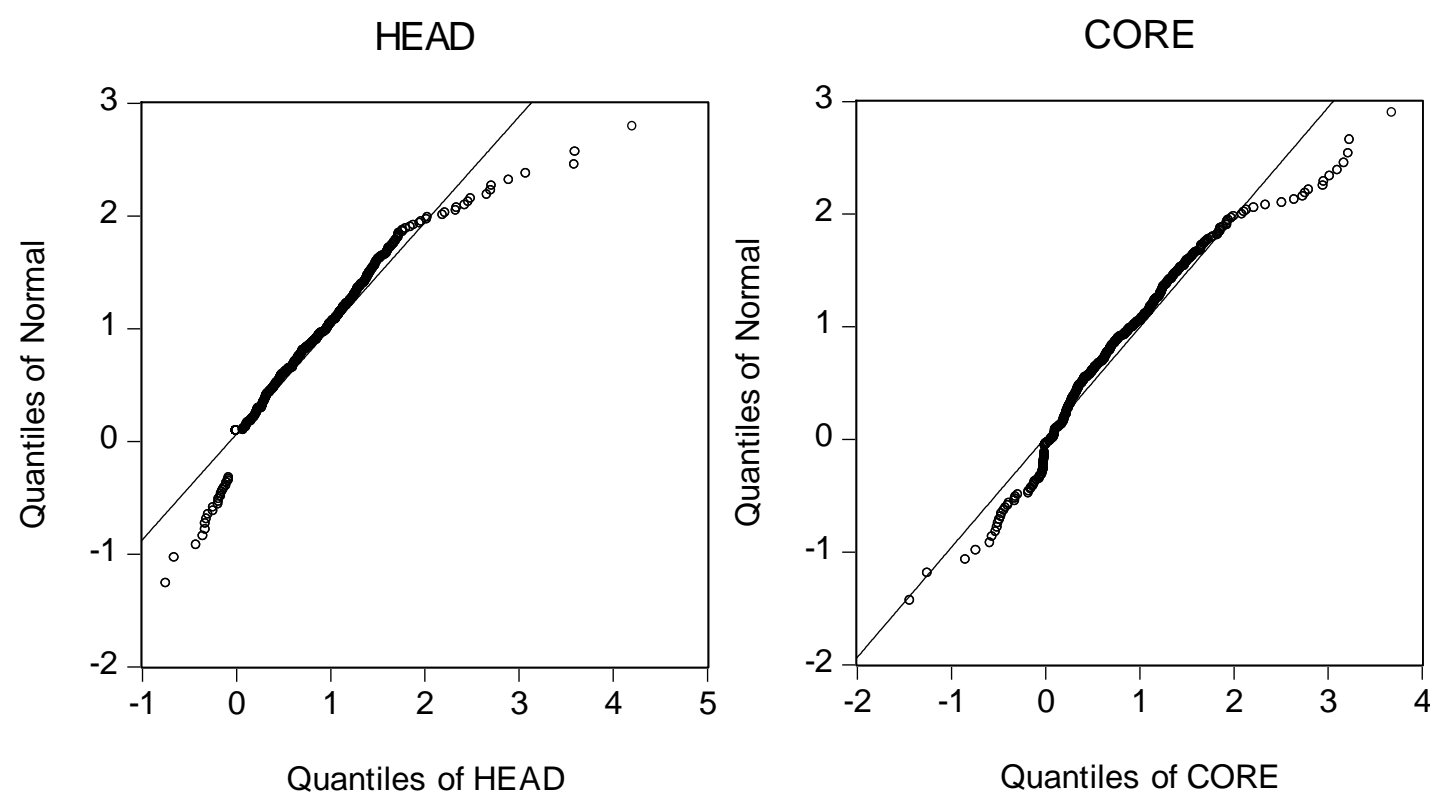

Figure 2: Density plots

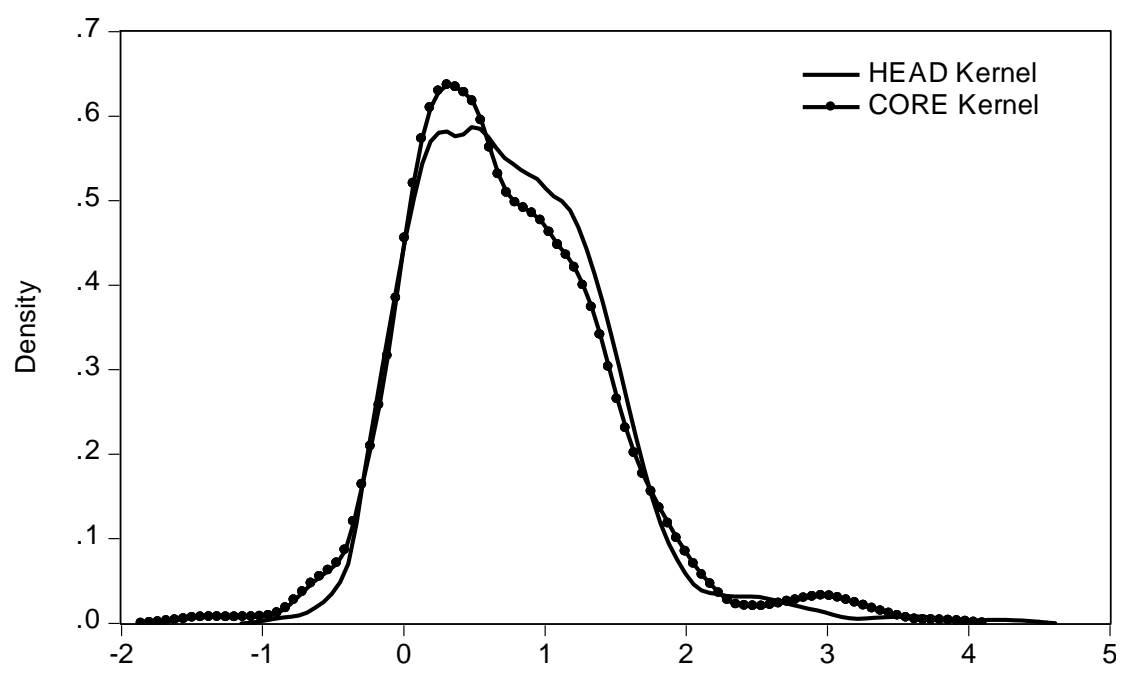


Figure 3: Quantile intercepts $\left(\alpha_{0}(\tau)\right)$ and autoregressive coefficients $\left(\rho_{1}(\tau)\right)$ for the period 1975:02-2015:04

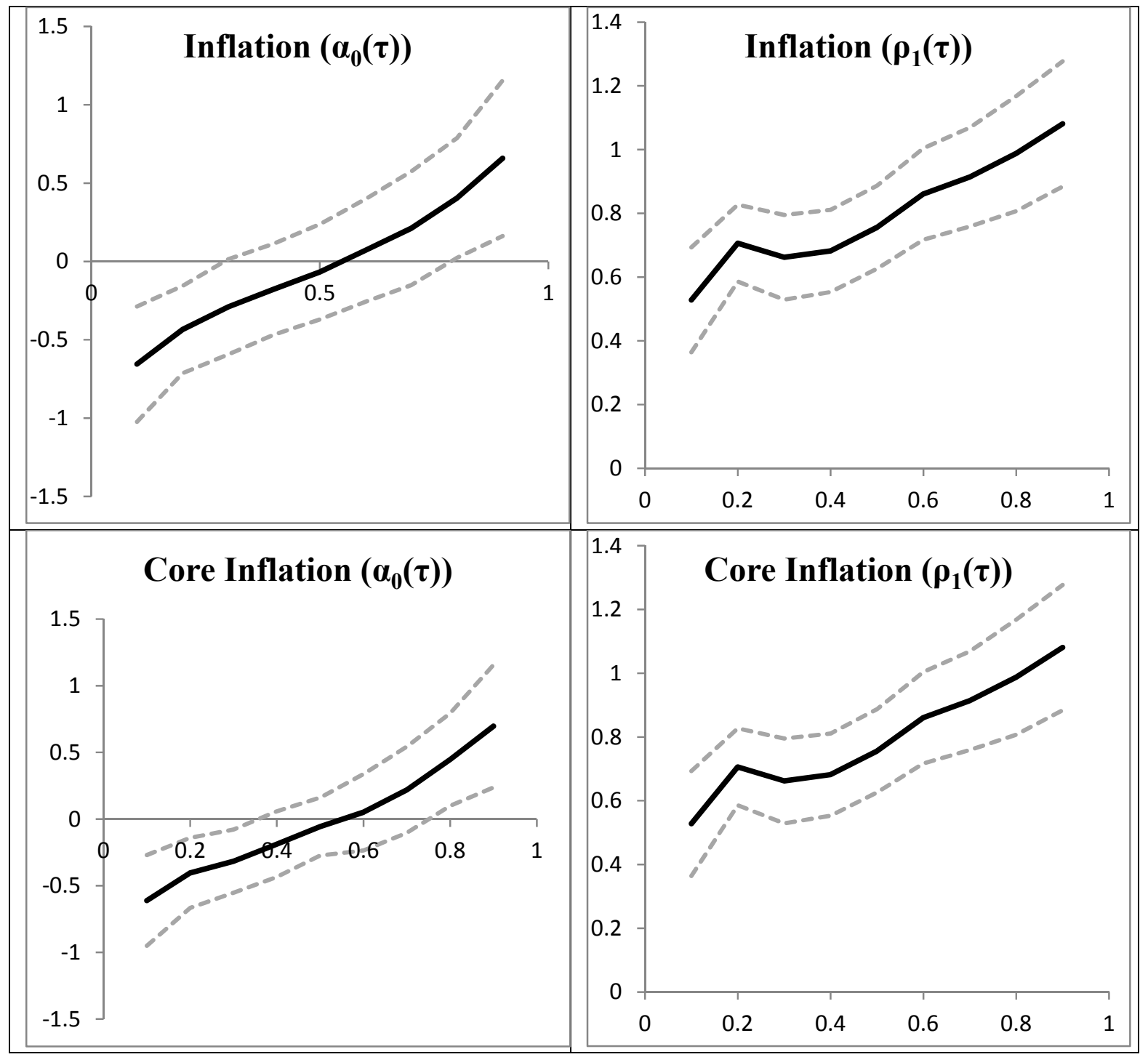

Note: Solid lines are the values of $\rho_{1}(\tau)$ and $\alpha_{0}(\tau)$ and dashed lines are their $95 \%$ confidence intervals. 
Figure 4: Quantile intercepts $\left(\alpha_{0}(\tau)\right)$ and autoregressive coefficients $\left(\rho_{1}(\tau)\right)$ for the period 1975:02-1992:04

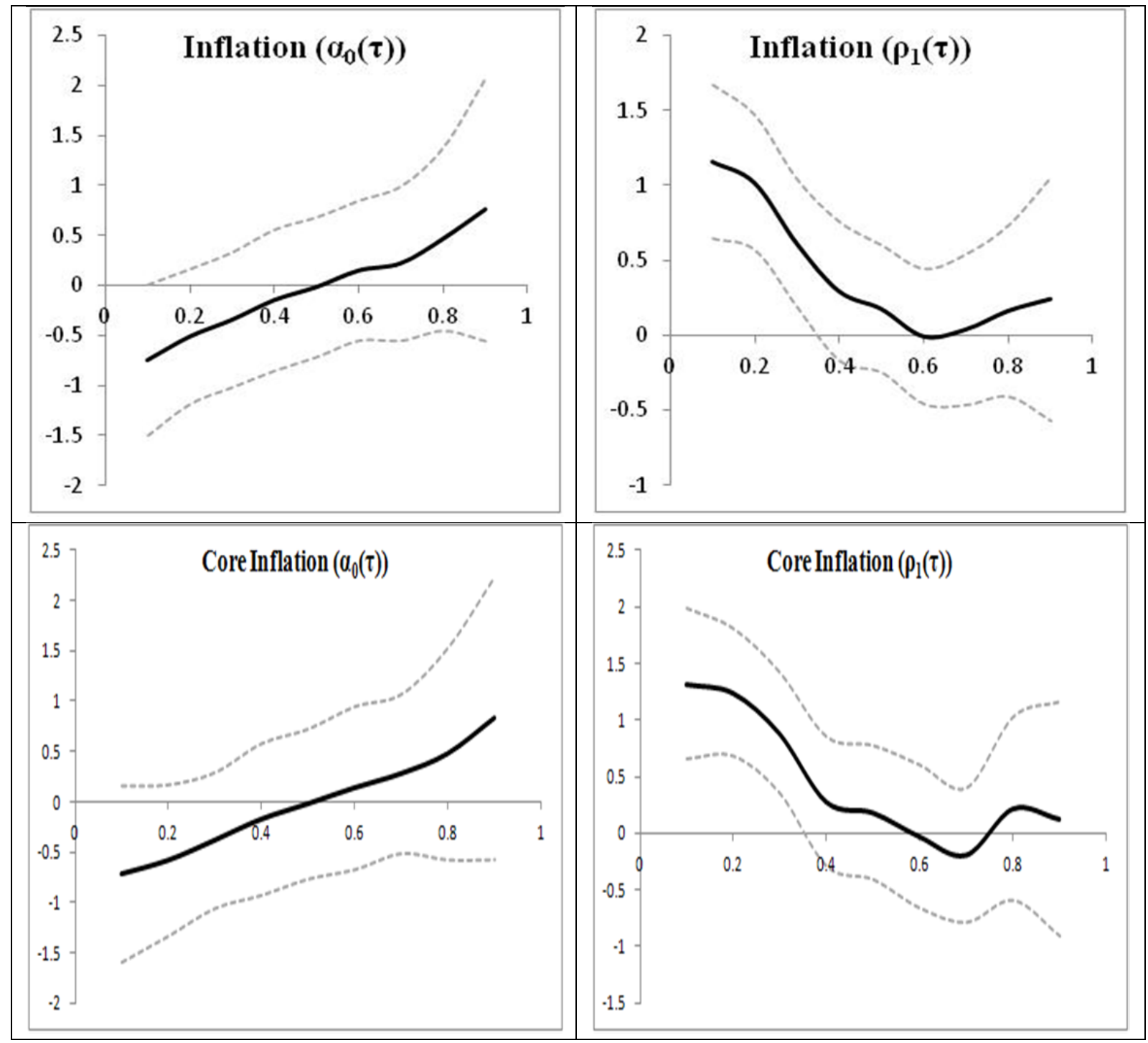

Note: See Notes to Figure 3. 
Figure 5: Quantile intercepts $\left(\alpha_{0}(\tau)\right)$ and autoregressive coefficients $\left(\rho_{1}(\tau)\right)$ for the period 1992:052015:04

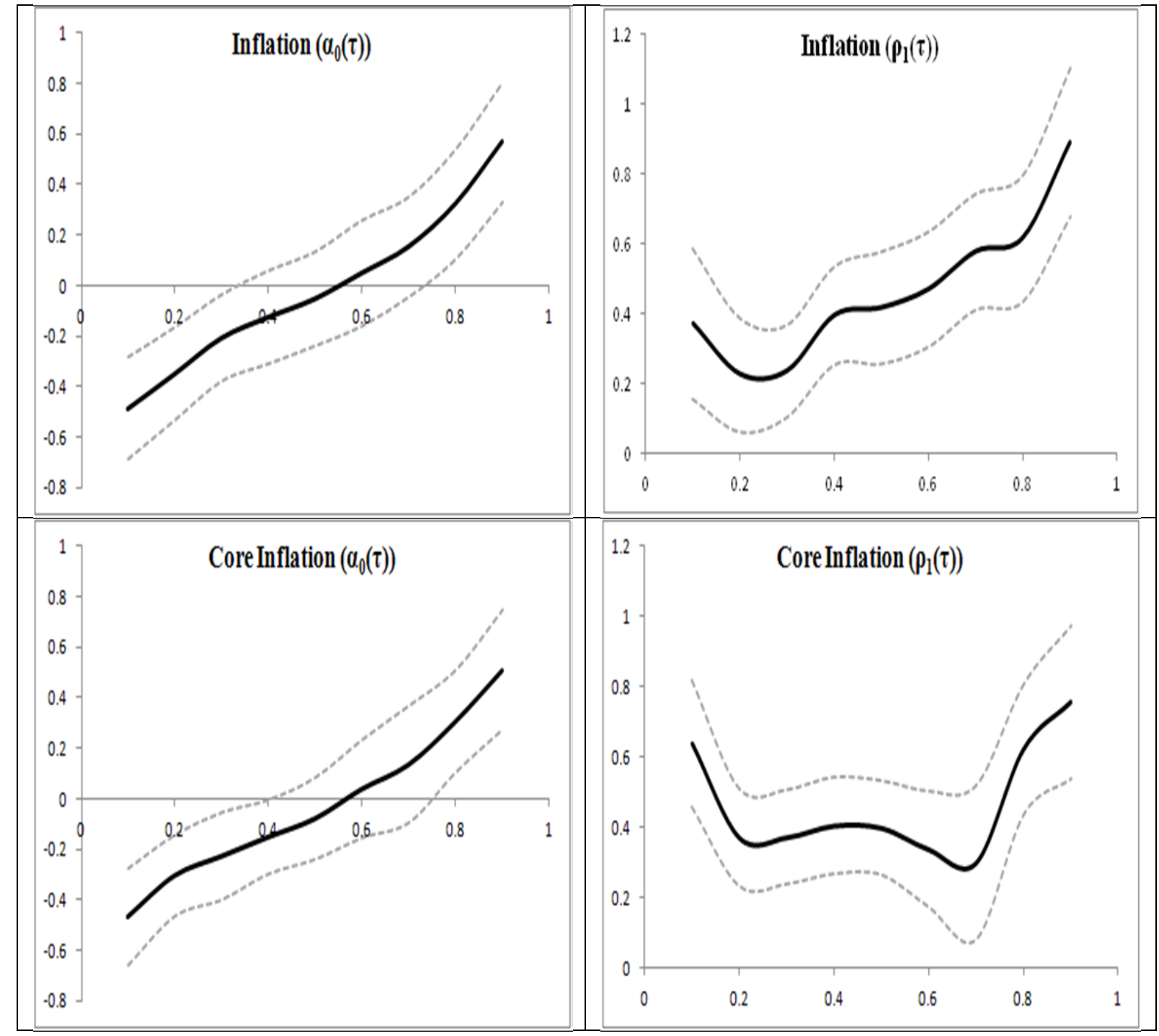

Note: See Notes to Figure 3. 
Figure 6: Quantile intercepts $\left(\alpha_{0}(\tau)\right)$ and autoregressive coefficients $\left(\rho_{1}(\tau)\right)$ for the period 1975:021999:12

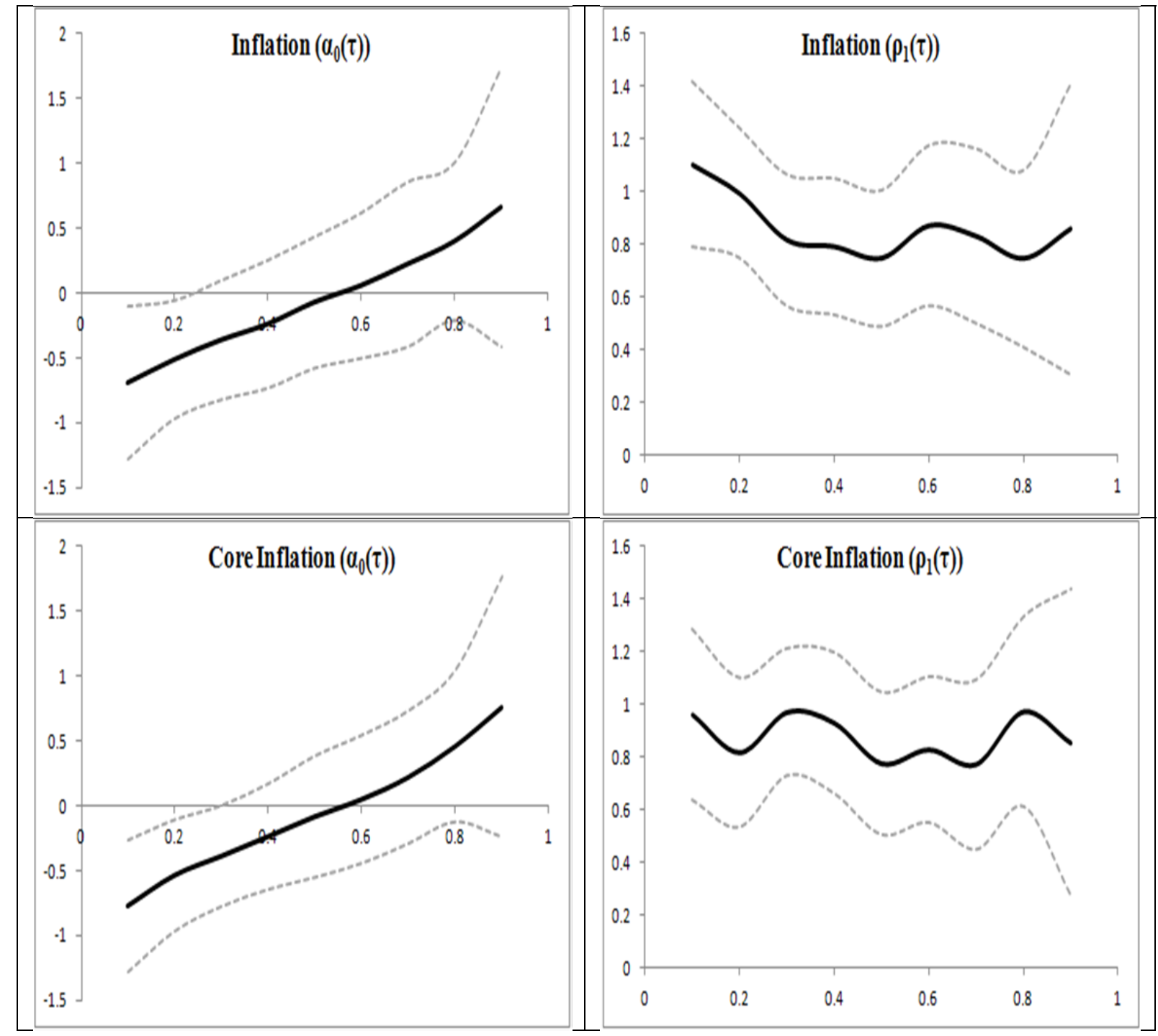

Note: See Notes to Figure 3. 
Figure 7: Quantile intercepts $\left(\alpha_{0}(\tau)\right)$ and autoregressive coefficients $\left(\rho_{1}(\tau)\right)$ for the period 2000:012015:04

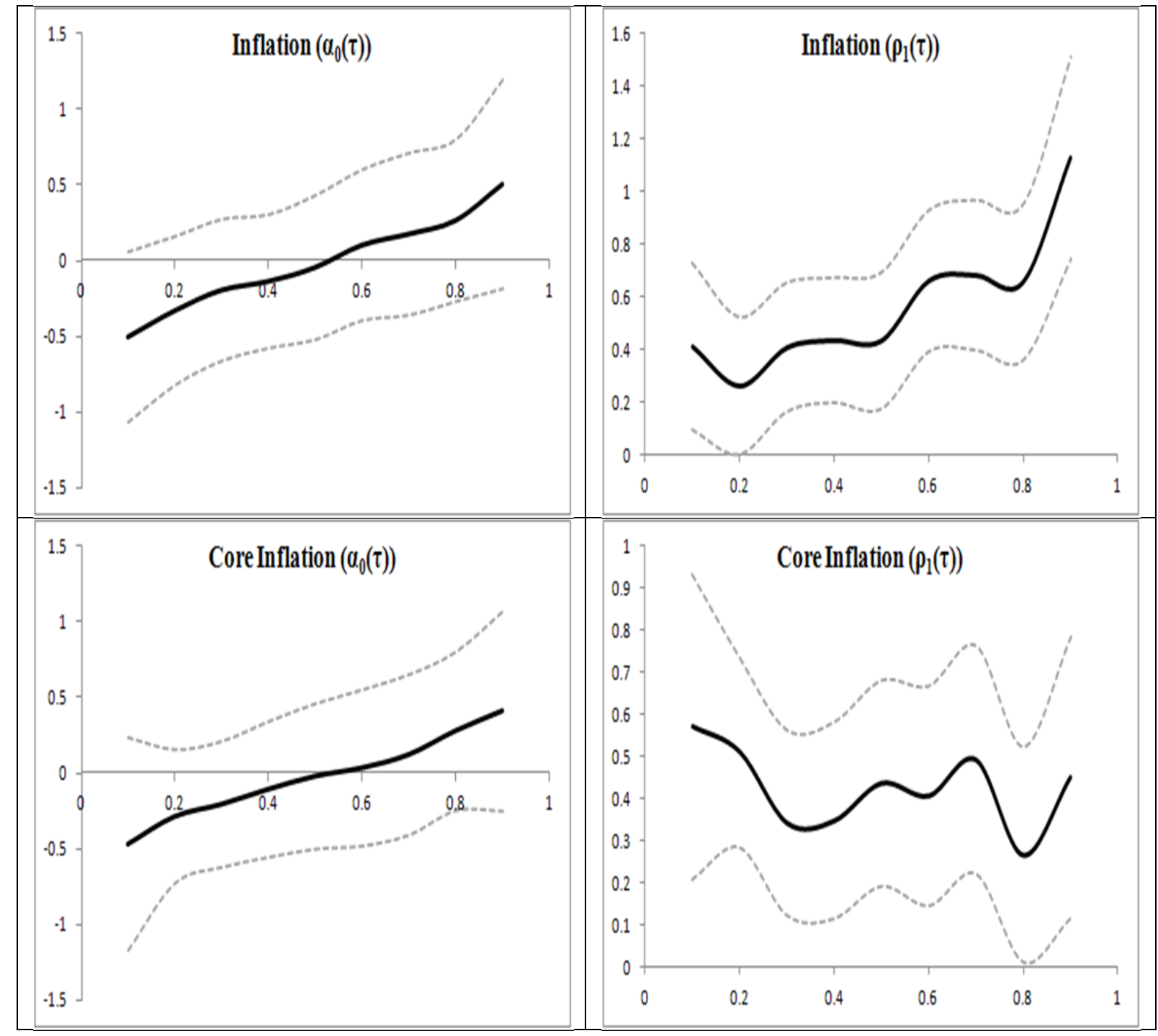

Note: See Notes to Figure 3. 